\title{
ESTUDO DA VIABILIDADE DE APLICAÇÃO DO CARVÃO ATIVADO DE OSSOS BOVINOS PARA DEFLUORETAÇÃO DE ÁGUA SUBTERRÂNEA
}

\author{
I. C. S. $\operatorname{COSTA}^{1}$, M. E. O. FONSECA ${ }^{1}$ e P. L. MESQUITA ${ }^{1}$ \\ ${ }^{1}$ Universidade Federal de São João Del Rei, Departamento de Engenharia Química \\ E-mail para contato: costaisa07@gmail.com
}

\begin{abstract}
RESUMO - A escassez de água é um problema que afeta diversas regiões no mundo e que se torna mais crítico em regiões mais pobres. Neste contexto, água do tipo subterrânea se torna em algumas dessas regiões a mais importante ou mesmo única fonte de água para consumo da população. Entretanto, esse tipo de água não se encontra, na maioria das vezes, adequada aos padrões de potabilidade, ou seja, própria para consumo. O fluoreto é um exemplo de substância que pode ser encontrado nessas águas e que se presente em concentrações superiores a 1,5 $\mathrm{mg} / \mathrm{L}$, pode causar fluorose dentária e esquelética, além de doenças nas glândulas endócrinas, fígado e tireoide. Assim, este trabalho tem como objetivo estimar o custo operacional decorrente da implantação no tratamento da água de uma etapa de defluoretação com carvão ativado de ossos bovinos. Esse tipo de carvão ativado apresenta maior capacidade de adsorção de fluoreto e menor custo em relação ao carvão ativado convencional. A estimativa foi realizada para algumas cidades pertencentes ao denominado Polígono das Secas no estado de Minas Gerais. Nessas cidades o abastecimento era proveniente de fonte de água subterrânea com concentração de fluoreto superior aos padrões estabelecidos. Os resultados obtidos mostraram que a aplicação do carvão de osso no processo de adsorção de fluoreto é mais viável quando comparado ao uso de carvão ativado convencional.
\end{abstract}

\section{INTRODUÇÃO}

A escassez de água é um problema que afeta diversas regiões no mundo e que se torna mais crítico em regiões mais pobres. A água utilizada para o consumo da população nessas regiões não se encontra, na maioria das vezes, adequada aos padrões de potabilidade exigidos pelo Ministério da Saúde (2005). Dessa forma, a incidência de doenças endêmicas acometidas pela baixa qualidade da água é alta (Diniz, 2006). Soma-se a isto, o descarte indevido de efluentes industriais e domésticos que contamina os mananciais e pode, portanto, restringir o uso dessa fonte de água para consumo.

Neste contexto, as águas subterrâneas se tornam importante fonte de água para a população. Esse tipo de recurso tem sua composição relacionada diretamente com o tipo do solo da região em que é encontrado. O fluoreto é um exemplo de substância que pode ocorrer naturalmente em águas, devido às características da geoquímica do solo, ou pode ser proveniente do descarte de efluentes industriais, e que se presente em água destinada para 
consumo em concentrações superiores a $1,5 \mathrm{mg} / \mathrm{L}$, pode causar fluorose dentária e esquelética, além de doenças nas glândulas endócrinas, fígado e tireoide (Tovar-Gómez et.al, 2013).

Desse modo, no tratamento de águas subterrâneas deve ser avaliada a implantação de uma etapa de defluoretação para águas com níveis de fluoreto acima do limite permitido pelo Ministério da Saúde. O processo de adsorção é uma das alternativas a serem empregadas, no entanto ainda apresenta um maior custo quando comparado a outras técnicas, em decorrência principalmente do tipo de adsorvente utilizado. Desse modo, fontes alternativas de matéria prima para a produção de carvão ativado são pesquisadas, visando à obtenção de uma melhor relação custo/benefício. Nesse contexto, o carvão ativado de ossos bovinos, é uma das opções investigadas para ser empregada em substituição ao carvão ativado convencional.

\section{OBJETIVO}

Avaliar a viabilidade do uso de carvão ativado de ossos bovinos na defluoretação de água para consumo humano em comparação ao processo realizado com o uso do carvão ativado convencional.

\section{PROCEDIMENTO EXPERIMENTAL}

\subsection{Capacidade máxima adsortiva}

O valor médio para a capacidade máxima adsortiva $\left(\mathrm{q}_{\mathrm{m}}\right)$ de fluoreto em carvão de osso foi determinado a partir de estudos revisados para a defluoretação de água. Na Tabela 1, são apresentados os valores estimados nesses trabalhos, para condições de temperatura e pH similares, a partir do ajuste dos dados experimentais ao modelo de adsorção de Langmuir.

Tabela 1 - Capacidade adsortiva máxima do carvão de osso estimada em diferentes trabalhos reportados na literatura.

\begin{tabular}{|c|c|c|}
\hline $\begin{array}{c}\text { Artigos Científicos revisados } \\
\text { - Defluoretação de água em } \\
\text { carvão ativado de osso }\end{array}$ & $\begin{array}{c}\text { Quantidade de carvão utilizada } \\
\left(\mathrm{g} \mathrm{L}^{-1}\right)\end{array}$ & $\begin{array}{c}\text { Capacidade máxima adsortiva - } \\
\mathrm{q}_{\mathrm{m}}\left(\mathrm{mg} \mathrm{g}^{-1}\right)\end{array}$ \\
\hline \hline Leyva-Ramos et al. (2010) & 1,00 & $\begin{array}{c}\mathrm{d}_{\mathrm{p}}^{(1)}(0,65 \mathrm{~mm})-5,70 \\
\mathrm{~d}_{\mathrm{p}}(0,79 \mathrm{~mm})-5,46 \\
\mathrm{~d}_{\mathrm{p}}(1,29 \mathrm{~mm})-5,89\end{array}$ \\
\hline Tovar-Gómez et al. (2013) & 10 & $\begin{array}{c}\mathrm{BCB}^{(2)}-3,614 \\
\mathrm{BCM}^{(3)}-4,510\end{array}$ \\
\hline Ribeiro (2011) & 2 & $\begin{array}{c}\text { Carvão "in natura" - 2,96 } \\
\text { Carvão lavado - 3,44 }\end{array}$ \\
\hline Medellin-Castillo et al. (2007) & 2,18 & 5,44 \\
\hline
\end{tabular}

Já a capacidade máxima adsortiva do carvão ativado convencional foi obtida no trabalho de Tchomgui-Kamga et al. (2010), sendo reportado o valor de 1,10 $\mathrm{mg} \mathrm{g}^{-1}$.

\subsection{Estimativa do custo operacional}

Diniz (2006) realizou um mapeamento no estado de Minas Gerais que identificou a presença de fluoreto em concentração superior ao limite estabelecido pelo Ministério da 
Saúde (2005) em águas subterrâneas de diversos municípios do estado. A situação é crítica nos municípios que fazem parte do Polígono das Secas no norte e nordeste do estado, uma vez que a maior parte da água utilizada nessa região é de fonte subterrânea.

A partir desses dados e do relatório anual de qualidade de água da Copasa (2014), que descreve a fonte de água utilizada no abastecimento de cada cidade, foi possível identificar as cidades em que o abastecimento era proveniente de água subterrânea com concentração de fluoreto superior aos padrões estabelecidos. Portanto, para essas cidades foi feita a estimativa do custo operacional decorrente da implantação de uma etapa de defluoretação no processo de tratamento da água. No relatório da Copasa (2014), também consta a vazão de água diária e quantidade de habitantes beneficiados por cidade. Na Tabela 2, estão apresentados os valores da vazão de água (L/dia), o número de beneficiários e a concentração de fluoreto $(\mathrm{mg} / \mathrm{L})$ da fonte de água subterrânea para cada uma das cidades avaliadas.

Tabela 2 - Valores de vazão de água (L/dia), número de habitantes e concentração de fluoreto $(\mathrm{mg} / \mathrm{L})$ para cada cidade avaliada neste trabalho

\begin{tabular}{|c|c|c|c|}
\hline Cidade & $\begin{array}{c}\text { Vazão de água }\left(10^{6}\right. \\
\text { L/dia) }\end{array}$ & $\begin{array}{c}\text { Quantidade de } \\
\text { beneficiários }\end{array}$ & $\begin{array}{c}\text { Concentração de fluoreto } \\
\text { (mg/L) }\end{array}$ \\
\hline \hline Araçuaí & 4 & 30.043 & 2,1 \\
\hline Caratinga & 14,25 & 71.546 & 2,0 \\
\hline Espinosa & 4,1 & 23.165 & 4,25 \\
\hline Ibiaí & 1,21 & 6.915 & 2,0 \\
\hline Itapeva & 2,45 & 6.774 & 1,70 \\
\hline Lagoa Santa & 12 & 46.760 & 1,6 \\
\hline Medina & 2,2 & 18.312 & 2,3 \\
\hline Montalvânia & 2,94 & 8.590 & 1,8 \\
\hline Porteirinha & 4,3 & 26.282 & 1,75 \\
\hline
\end{tabular}

$\mathrm{Na}$ Tabela 3, estão apresentados os preços $(\mathrm{R} \$ / \mathrm{Kg})$ para o carvão bovino granulado e pulverizado fornecido pela Bonechar ${ }^{\circledR}$ e o preço médio do carvão ativado convencional granulado e pulverizado com base na cotação fornecida pela Alphacarbo e Guaramex.

Tabela 3 - Relação dos preços $(\mathrm{R} \$ / \mathrm{Kg})$ do carvão de osso bovino e carvão ativado convencional, fornecidos pela Bonechar ${ }^{\circledR}$ e Alphacarbo/Guaramex respectivamente

\begin{tabular}{|c|c|c|}
\hline \multirow{2}{*}{ Fornecedor } & Tipo de carvão & Preço (R\$/Kg) \\
\hline \multirow{2}{*}{ Bonechar } & Granulado & 5,50 \\
\cline { 2 - 3 } & Pulverizado & 3,80 \\
\hline \multirow{2}{*}{ Alphacarbo/Guaramex } & Granulado & 5,75 \\
\cline { 2 - 3 } & Pulverizado & 4,15 \\
\hline
\end{tabular}

Já as Equações 1, 2 e 3 foram aplicadas para o cálculo da quantidade necessária de carvão para a remoção do fluoreto da água para concentrações abaixo do limite estabelecido.

$$
C_{i} * \dot{V}-C_{f} * V=\dot{m}_{r}
$$




$$
\begin{aligned}
& \dot{m}_{r} / Q_{\max }=\dot{m}_{c} \\
& \dot{m}_{c} / N_{h}=\dot{m}_{h}
\end{aligned}
$$

Em que: $C_{i}$ - concentração inicial de flúor $\left(\mathrm{mg} \mathrm{L}^{-1}\right) ; C_{f}$ - concentração máxima final de flúor $\left(\mathrm{mg} \mathrm{L}^{-1}\right) ; \dot{V}$ - vazão de água necessária para abastecer a cidade $\left(\mathrm{L} \mathrm{dia}^{-1}\right) ; \dot{m}_{r}$ - massa de flúor adsorvida (mg); $\dot{m}_{c}$ - massa de carvão necessária; $N_{h}$ - número de habitantes da cidade e $\dot{m}_{h}$ massa de carvão por habitantes (mg hab $\left.{ }^{-1} \mathrm{dia}^{-1}\right)$.

A estimativa de custo para as cidades avaliadas foi obtida conforme a Equação 4.

$$
\dot{m}_{h} * P=P_{h}
$$

Em que: $\dot{m}_{h}$ - quantidade de carvão ativado de osso ou de carvão convencional necessário para a defluoretação da água $\left(\mathrm{Kg} \mathrm{hab}^{-1} \mathrm{dia}^{-1}\right) ; P$ - preço do carvão ativado de osso ou convencional $\left(\mathrm{R} \$ \mathrm{Kg}^{-1}\right)$ e $P_{h}$ - estimativa de custo por habitante por dia para o tratamento de água para consumo $\left(\mathrm{R} \$ \mathrm{hab}^{-1} \mathrm{dia}^{-1}\right)$.

\section{RESULTADOS E DISCUSSÃO}

$\mathrm{Na}$ Tabela 4, estão apresentados os valores obtidos para a quantidade de adsorvente e o custo estimado da defluoretação de água em carvão ativado de osso.

Tabela 4 - Valores estimados para a quantidade de carvão de osso necessária para a defluoretação, com as respectivas estimativas de custo do processo para carvão ativado de osso granular e pulverizado

\begin{tabular}{|c|c|c|c|}
\hline Cidade & $\begin{array}{c}\text { Quantidade de Carvão } \\
(\mathrm{kg} / \mathrm{hab} . \text { dia })\end{array}$ & $\begin{array}{c}\text { Granulado } \\
(\mathrm{R} \$ / \text { hab.dia })\end{array}$ & $\begin{array}{c}\text { Pulverizado } \\
(\mathrm{R} \$ / \text { hab.dia })\end{array}$ \\
\hline \hline Araçuaí & $3,9 \times 10^{-2}$ & 0,21 & 0,15 \\
\hline Caratinga & $5,45 \times 10^{-3}$ & 0,03 & 0,02 \\
\hline Espinosa & $1,33 \times 10^{-1}$ & 0,73 & 0,51 \\
\hline Ibiaí & $4,70 \times 10^{-2}$ & 0,26 & 0,18 \\
\hline Itapeva & $7,43 \times 10^{-2}$ & 0,41 & 0,28 \\
\hline Lagoa Santa & $4,70 \times 10^{-2}$ & 0,26 & 0,18 \\
\hline Medina & $4,04 \times 10^{-2}$ & 0,22 & 0,15 \\
\hline Montalvânia & $7,78 \times 10^{-2}$ & 0,43 & 0,30 \\
\hline Porteirinha & $3,54 \times 10^{-2}$ & 0,19 & 0,13 \\
\hline
\end{tabular}

Já na Tabela 5, estão apresentados os valores obtidos para a quantidade de carvão convencional e o custo estimado da defluoretação de água com o uso desse adsorvente. 
Tabela 5 - Valores estimados para a quantidade de carvão convencional necessária para a defluoretação, com as respectivas estimativas de custo do processo para carvão ativado granular e pulverizado

\begin{tabular}{|c|c|c|c|}
\hline Cidade & $\begin{array}{c}\text { Quantidade de carvão } \\
(\mathrm{kg} / \mathrm{hab} . d i a)\end{array}$ & $\begin{array}{c}\text { Granulado } \\
(\mathrm{R} \$ / \text { hab.dia })\end{array}$ & $\begin{array}{c}\text { Pulverizado } \\
\text { (R\$/hab.dia) }\end{array}$ \\
\hline \hline Araçuaí & $1,63 \times 10^{-1}$ & 0,94 & 0,68 \\
\hline Caratinga & $2,24 \times 10^{-2}$ & 0,13 & 0,09 \\
\hline Espinosa & $5,61 \times 10^{-1}$ & 3,23 & 2,33 \\
\hline Ibiaí & $1,98 \times 10^{-1}$ & 1,14 & 0,82 \\
\hline Itapeva & $3,13 \times 10^{-1}$ & 1,80 & 1,30 \\
\hline Lagoa Santa & $1,98 \times 10^{-1}$ & 1,14 & 0,82 \\
\hline Medina & $1,70 \times 10^{-1}$ & 0,98 & 0,71 \\
\hline Montalvânia & $3,30 \times 10^{-1}$ & 1,90 & 1,37 \\
\hline Porteirinha & $1,50 \times 10^{-1}$ & 0,86 & 0,62 \\
\hline
\end{tabular}

Os custos estimados para defluoretação em carvão de osso foram em média quatro vezes inferiores aos custos obtidos para o carvão convencional. Essa proporção relaciona-se diretamente com a capacidade máxima adsortiva de cada tipo de carvão ativado. O carvão ativado de osso apresentou, segundo os estudos revisados, uma capacidade média adsortiva de $4,63 \mathrm{mg} / \mathrm{g}$, em contraposição ao valor de $1,10 \mathrm{mg} / \mathrm{g}$ reportado na literatura para a capacidade máxima adsortiva do carvão ativado convencional. Como o preço do carvão de osso e do carvão ativado convencional são relativamente próximos, o fator de maior influência no custo da defluoretação é a diferença na capacidade de adsorção de fluoreto entre os materiais.

Dentre as cidades avaliadas, Espinosa apresentou o maior custo da defluoretação, uma vez que sua fonte de água subterrânea possui concentração de fluoreto aproximadamente duas vezes maior que o valor correspondente às outras cidades. Já Caratinga apresentou o custo mais baixo para o processo de defluoretação, o que se justifica não apenas por sua concentração de fluoreto na água de $2 \mathrm{mg} / \mathrm{L}$, já que não representa a cidade com menor concentração de fluoreto na água, mas que se relaciona principalmente com o valor baixo da proporção entre a vazão de água e o número de habitantes

As estimativas de custo demonstraram que o uso de carvão ativado de osso e convencional pulverizado é mais viável que o uso de carvão granular, no entanto deve-se ressaltar que o carvão quando em forma granular pode ser reutilizado até que a saturação máxima seja atingida, ao contrário do carvão pulverizado que é usado apenas uma única vez para durante o processo de defluoretação.

\section{CONCLUSÃO}

Os resultados corroboram a viabilidade do uso de carvão ativado de osso na defluoretação de água, que conforme Medellin-Castillo et al. (2007) é juntamente com a alumina ativada o adsorvente disponível comercialmente que apresenta maior eficiência na remoção de fluoreto de água. No trabalho realizado por ABE et al. (2004) foi demonstrado o quanto a capacidade máxima adsortiva de fluoreto em carvão osso é maior que a apresentada por carvão ativado convencional, sendo também superior aos valores obtidos com outros tipos de materiais adsorventes. Tchomgui-Kamga et al. (2010) encontrou para carvão de cálciosuportado e carvão ativado modificado com $\mathrm{KMnO}_{4}$, uma capacidade máxima adsortiva de 
fluoreto superior ao carvão de osso. No entanto, esses adsorventes não são produzidos em escala comercial, já que ainda possuem um custo relativamente superior ao carvão ativado convencional.

\section{REFERÊNCIAS BIBLIOGRÁFICAS}

ABE, I. et al. Adsorption of fluoride ions onto carbonaceous materials. Journal of Colloid and Interface Science 275, p. 35-39, 2004.

Alphacarbo. Disponível em: http://alphacarbo.com.br/. Acesso em: 23 de janeiro de 2014.

Bonechar do Brasil - Carvão Ativado. Disponível em: http://www.bonechar.com.br. Acesso em: 13 de janeiro de 2014.

DINIZ, LUCIANA GALUPPO. O flúor nas águas subterrâneas do estado de Minas Gerais. Dissertação (Mestrado em Geologia). Universidade Federal de Minas Gerais - Instituto de Geociências. Programa de Pós-Graduação em Geologia. Belo Horizonte, 2006.

Guaramex. Disponível em: http://www.guaramex.com.br/. Acesso em: 23 de janeiro de 2014.

Leyva-Ramos, R. et al. Kinetic modeling of fluoride adsorption from aqueous solution onto bone char. Chemical Engineering Journal 158, p. 458-467, 2010.

MEDELLIN-CASTILLO, N.A et al. Adsorption of Fluoride from Water Solution on Bone Char. Ind. Eng. Chem. Res. 46, p. 9205-9212, 2007.

Ministério da Saúde. Portaria MS n. ${ }^{\circ}$ 518/2004. Série E. Legislação de Saúde. Brasília - DF, 2005.

Relatório Anual de Qualidade de Água, COPASA. Disponível em: http://www2.copasa.com.br/servicos/relatorioqualidade/consulta.asp. Acesso: $12 \mathrm{de}$ maio de 2014.

RIBEIRO, M.V. Uso de carvão de osso bovino na defluoretação de água para uso em abastecimento público. Dissertação (Mestrado) - Universidade Federal de Minas Gerais. Programa de Pós-Graduação em Engenharia Metalúrgica e de Minas. Belo Horizonte, MG, 2011.

TCHOMGUI-KAMGA E.; NGAMENI E.; DARCHEN A. Evaluation of removal efficiency of fluoride from aqueous solution using new charcoals that contain calcium compounds. Journal of Colloid and Interface Science 346 (2010) 494-499.

TOVAR-GÓMEZ, R. et al. Modeling of fixed-bed adsorption of fluoride on bone char using a hybrid neural network approach. Chemical Engineering Journal 228, p. 1098-1109, 2013. 